\title{
Potential vegetable sources for biodiesel production: cashew, coconut and cotton
}

\author{
Jennifer Judith Lafont • Amelia Andrea Espitia • \\ José Ricardo Sodré
}

Received: 26 April 2014/Accepted: 19 December 2014/Published online: 27 January 2015

(C) The Author(s) 2015. This article is published with open access at Springerlink.com

\begin{abstract}
This work presents a study on crude oil and biodiesel obtained from the seeds of the tropical plants Anacardium occidentale L (cashew), Cocos nucifera (coconut palm) and Gossypium hirsutum (upland cotton). The following crude oil and biodiesel physical-chemical properties were determined: acid number, iodine value, copper corrosivity, density and viscosity at different temperatures. Also, the chemical composition of the fatty acid methyl esters was measured using gas chromatography and a comparison was made with biodiesel from other sources reported in the literature. The analysis pointed out that cashew, coconut palm and upland cotton are potential sources for biodiesel production. Among the biodiesel types tested, cashew showed the highest oxidation stability.
\end{abstract}

Keywords Biodiesel $\cdot$ Cashew $\cdot$ Coconut $\cdot$ Cotton · Fatty acid

\section{Introduction}

The world energy demand and environmental contamination have both increased throughout the years from the

\section{J. J. Lafont · A. A. Espitia}

Department of Chemistry, University of Cordoba,

Carrera 6, No 76-103, Monterìa, Córdoba, Colombia

e-mail: jenniferlafontmendoza@gmail.com

A. A. Espitia

e-mail: andreaespitia36@gmail.com

\section{J. R. Sodré $(\varangle)$}

Department of Mechanical Engineering, Pontifical Catholic University of Minas Gerais, Av. Dom José Gaspar 500, Belo Horizonte, MG 30535-901, Brazil

e-mail: ricardo@pucminas.br increase of global warming gases and particles suspension in the atmosphere. The main reason is the use of fossil fuels as energy source for the development of industrial, technological, economical, transport and agricultural activities, among others [1]. This situation produced the search for alternative and renewable energy sources, such as biodiesel. Biodiesel is a biofuel, the chemical composition of which is a blend of alkyl esters produced together with glycerin from esterification or transesterification reactions of free fatty acids and triglycerides present in vegetable oils or animal fat [2].

Vegetable oils are the most studied ones for biodiesel production, among them palm, soybean, rapeseed and sunflower [3]. Other oleaginous plants have recently been considered for biodiesel production, such as Anacardium occidentale $L$. This is popularly known as cashew, belonging to the Anacardiaceous group, typical from tropical zone, and it presents excellent nutritional and medical properties. Its fruit contains $\mathrm{A}$ and $\mathrm{C}$ vitamins and it is used to elaborate juices. The fruit is united to a pseudo fruit of gray color that has two types of oils, one of them, of black color, is viscous and corrosive due to the presence of anacardic acids, used as insect repellent. The other is light amber, with high concentration of fatty acids, and it has started to be studied as a potential biodiesel source [4]. The fatty acid composition of Anacardium occidentale $L$ has previously been reported by $[5,6]$.

Cocos nucifera is a palm tree commonly known as coconut, belonging to the Arecaceae group. It grows in tropical climate and humid atmosphere. Its thin trunk can reach $20 \mathrm{~m}$ tall, and its large fruit can have $20-30 \mathrm{~cm}$ of diameter, with a fibrous skin, inside which is the fruit of nut of oval shape, light brown color and hollow, that is filled with a juice during its growth. This fruit is used to obtain oil and its juice is used in refreshing drinks [7]. Previous work on coconut biodiesel has been presented by [5, 8]. 
The Gossypium hirsutum, known as upland cotton, is a bush belonging to the malvaceae group that can achieve $2 \mathrm{~m}$ tall. Its flowers are yellow and, when fecundated, change to pink. After withering they turn into fruits, which are capsules of 3-5 pistils with 6-10 seeds in each of them. As the seeds are mature, their epidermis generates the cellulosic fibers of cotton, which are important textile products. The seeds are also rich sources of oil and proteins, with high industrial value [9]. From these biodiesel sources, cotton is the only one that has been extensively studied by many researchers, among them [1, 2, 8, 10-13].

This paper presents an analysis of the physical-chemical properties of the crude oil and biodiesel produced from the tropical plants Anacardium occidentale L, Cocos nucifera and Gossypium hirsutum. The properties evaluated are acid number, iodine value, copper corrosion, density and viscosity. The methyl esters present in each biodiesel type are also investigated to verify if those are real potential sources for high-quality biofuel production. This work aims at giving further insight on the quality of biodiesel produced from those sources, considering that there is still a lack of information particularly for cashew and coconut.

\section{Methodology}

Reactants and samples

All solvents used in this work were of analytical grade, manufactured by Merck, distilled at reduced pressure before use. The tested samples were seeds of cashew (Fig. 1), upland cotton (Fig. 2) and coconut (Fig. 3), the plants of which were grown at the location of Montería, in Córdoba, Colombia.

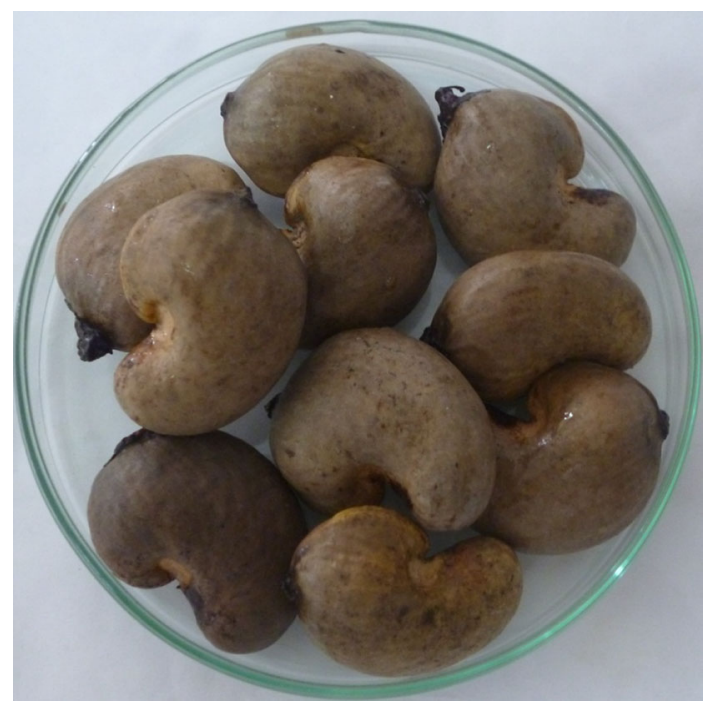

Fig. 1 Cashew seeds
Crude oil and biodiesel production

The tested cashew and cotton seeds were peeled and crunched by a milling machine. Then, they were dried at $105{ }^{\circ} \mathrm{C}$ during $30 \mathrm{~min}$ in a micro processing muffle model Terrígeno, of rated temperature $1,200{ }^{\circ} \mathrm{C}$, rated power $2.6 \mathrm{~kW}$ and maximum volume $8.8 \mathrm{~L}$. After drying, the crunched seeds were weighted and the drying procedure was repeated until the difference between the measured weights was below $0.05 \%$.

The dry sample (100 g) was submitted to an oil extraction process using hexane as a solvent. The solvent was recovered by a rotary evaporator. The concentrations of crude oil obtained were $77.88 \%$ for cashew and $75.63 \%$ for cotton. The coconut seed was grated and the

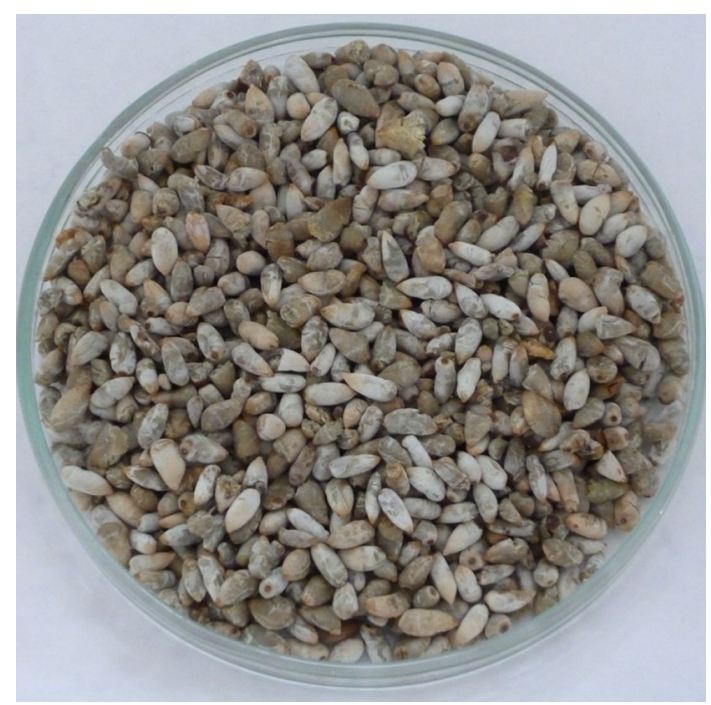

Fig. 2 Upland cotton seeds

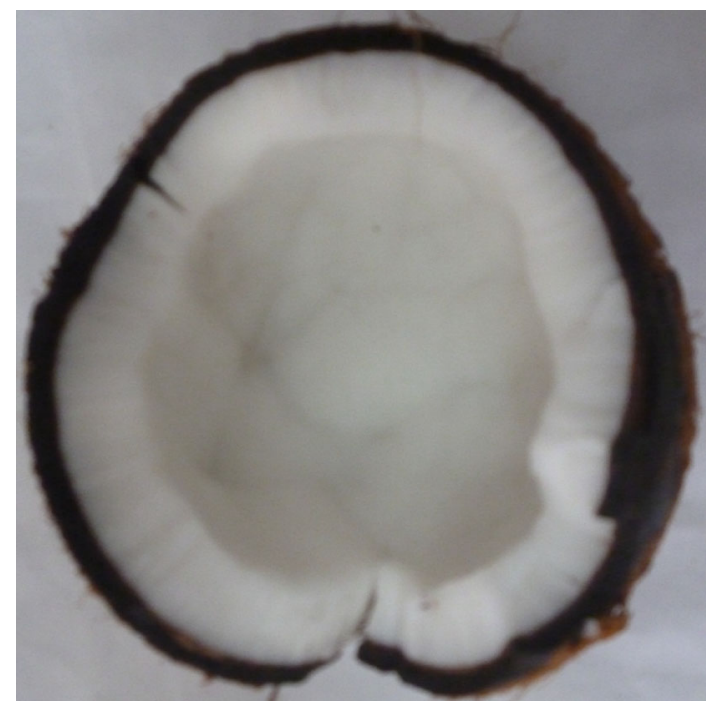

Fig. 3 Coconut seed interior 
oil was extracted at a warmed wet medium, from which $76.78 \%$ of crude oil was obtained.

The biodiesel was obtained from an esterification reaction in acid medium, followed by oil transesterification using methanol with a molar ratio of $6: 1$ and potassium hydroxide $(\mathrm{KOH})$ as a catalyst. With this purpose, $50 \mathrm{~mL}$ of oil was used together with a solution of methanol and $1 \%$ of $\mathrm{KOH}$, based on the oil amount. The solution was blended to the oil and the reaction was allowed to take place for 1-h at $210 \mathrm{rev} / \mathrm{min}$ and $328 \mathrm{~K}$. This procedure was performed three times. Afterwards, the solvent was recovered and the remaining substance was biodiesel-glycerol blend. This blend was taken to a separation funnel and remained still for $24 \mathrm{~h}$ to separate the biodiesel. The biodiesel was washed several times with hot deionized water to reach the neutrality. Finally, the biodiesel was warmed at $383 \mathrm{~K}$ during 10 min to eliminate humidity [12].

Identification and quantification of fatty acid methyl esters

The identification and quantification of the fatty acid methyl esters of all samples were performed using a gas chromatograph Agilent model 6,890 N with flame ionization detector (FID) analyzer. A capillary column model Carbowax $20 \mathrm{M}$ was used for separation of the sample components. The column had a nominal bore of $0.32 \mathrm{~mm}$ and a length of $30 \mathrm{~m}$, with $0.25 \mu \mathrm{m}$ wall film thickness and stationary phase poly ethylene glycol. The injected volume amount was $1 \mu \mathrm{L}$. The methodology applied is described by EN14103 standard. Methyl heptadecanoate was used as an internal standard substance. The fatty acid methyl esters present in the samples were identified by comparison with the retention times of the fatty acids of the standard substance.

Physical-chemical analysis of crude oil and biodiesel

The iodine value is a chemical property that describes the iodine mass absorbed by $100 \mathrm{~g}$ of sample. It is taken as a measure of the degree of unsaturation of the biodiesel. Once the iodine is added to the fatty acid double bonds, the iodine value is increased as the double bonds are increased. As a consequence, the biodiesel with high concentration of saturated fatty acids presents low iodine value, which is increased with mono-, di- and triunsaturates. When the biodiesel iodine value is high and the engine temperature is increased, the fuel is degraded faster and forms solid deposits in the engine. The iodine value was determined according to EN 14111 standard.

The acid number describes the amount of $\mathrm{KOH}$ required to neutralize the free fatty acids and other acid compounds present in a mass unit of biodiesel. The acid number was determined according to ASTM D664 standard. The acid number is considered as an indicator of biodiesel degradation. A high acid number affects engine fuel injection system and increases corrosion of engine components.

The peroxide index measures the initial oxidation of the fresh oil or the rancidity grade in equivalents of active oxygen per unit mass of oil, allowing for oxidation detection before organoleptic detection. The peroxide index is a measure of the oil degree of rancidity evolution, and was here determined according to AOAC Cd 8b-90 standard.

The saponification index is related to the molecular weight through the total fatty acids (free and combined) present in the oil sample. The saponification index was measured by the AOAC Cd 3-25 standard.

Humidity is an important oil factor that must be controlled. High humidity can generate a hydrolysis reaction of the triglycerides, forming free fatty acids that will contribute to a high acid value. Oil humidity was measured according to the AOAC 950.46 standard.

Copper corrosion is a parameter that allows for prediction of biodiesel corrosive action and detection of corrosive components or acids that attack some copper leagues, such as bronze, which are present in some engine components. Copper corrosion was determined following ASTM D130 standard.

Density is a property that can indicate the contamination degree of biodiesel. High biodiesel density can increase fuel consumption and generate higher amounts of gaseous pollutant emissions and particulate matter to the atmosphere. Also, the biodiesel density is an important parameter for storage and transportation as it can vary the fuel volume with varying temperature at a given pressure. The biodiesel viscosity must be minimized to avoid reduced engine power due to difficult flow through the filters and injectors of the fuel system. The biodiesel density and viscosity were determined according to ASTM D7042-12 standard.

The concentrations of total and free glycerin in biodiesel are important parameters to measure the biofuel quality. Low values of free glycerin reveal that high concentrations of methyl esters have been produced. On the other hand, the presence of glycerin with higher values than the standard limits indicates low conversion of the crude oil in biodiesel and poor fuel purification. The total and free glycerin content was measured by the AOCS Ca 14-56 standard.

Methanol content is another parameter that refers to the biodiesel purification degree. Low amounts of free methanol can reduce the fuel flammability index, oxidize the aluminum and zinc engine parts and cause damage to the fuel injection system. Methanol content was determined using EN14111 standard. 
The cetane number measures the biodiesel ignition quality, and is determined by ASTM D613 standard. To calculate its value, the correlation developed by Bamgboye and Hansen [14] from fatty acid profiles has been employed:

$$
\begin{aligned}
\mathrm{NC}= & 61.1+0.088 \mathrm{x}_{1}+0.133 \mathrm{x}_{2}+0.152 \mathrm{x}_{3}-0.101 \mathrm{x}_{4} \\
& -0.039 \mathrm{x}_{5}-0.243 \mathrm{x}_{6}-0.395 \mathrm{x}_{7}
\end{aligned}
$$

where $\mathrm{x}_{1}$ is the concentration of myristic acid (\%), $\mathrm{x}_{2}$ is the concentration of palmitic acid (\%), $\mathrm{x}_{3}$ is the concentration of stearic acid (\%), $\mathrm{x}_{4}$ is the concentration of palmitoleic acid (\%), $x_{5}$ is the concentration of oleic acid (\%), $x_{6}$ is the concentration of linoleic acid (\%) $\mathrm{x}_{7}$ is the concentration of linolenic acid (\%).

\section{Results and discussion}

The fatty acid profile of cashew biodiesel here measured is compared with the ones reported by [5, 6] (Table 1). The biodiesel chemical composition makes cashew a potential source for high-quality biodiesel production. A predominant concentration of oleic acid (C18:1) is observed. The oleic is a monounsaturated fatty acid that is favorable to oxidation stability, reducing degradation and polymerization. The oxidation process is favored by high number of double bonds to form the epoxides responsible for oil aging and it is typical of the oil types that present high concentrations of polyunsaturated fatty acids, such as linoleic acid (C18:2) and linolenic acid (C18:3).

Cashew biodiesel shows high concentration of oleic acid (C18:1) and low concentrations of linoleic acid (C18:2), linolenic acid (C18:3) and palmitic acid (C16:0), which is a saturated fatty acid not recommended as fuel for cold climate (Table 1). The results here found for cashew biodiesel are in close agreement with those found by $[5,6]$. In general, oleic acid (C18:1) was the component that showed the highest concentration (61.36-65.4\%), followed by linoleic acid (C18:2) (16-19.48 \%), palmitic acid (C16:0) $(10.36-10.5 \%)$ and stearic acid (C18:0) (7.2-9.04\%). Small concentrations of linolenic acid (C18:3) $(0.29-0.52 \%)$ have also been identified by this work and by [5]. Those authors also reported low concentrations of myristic (14:0), palmitoleic (16:1), arachidic (C21:0) and behenic acids (C22:0), all varying from $0.07-0.67 \%$. These components have not been reported by [6].

Coconut biodiesel composition shows a predominant concentration of lauric acid (C12:0) (46.91-64.44\%), followed by myristic acid (C14:0) (18.50-20.45\%) and palmitic acid (C16:0) (7.71-8.90\%) (Table 2). The presence of high concentrations of saturated fatty acids limits the use of coconut biodiesel at low temperatures. The
Table 1 Chemical composition of cashew biodiesel

\begin{tabular}{lcccc}
\hline Fatty acid & CC:DB & \multicolumn{3}{c}{ Cashew biodiesel composition (\%) } \\
\cline { 3 - 5 } & & This work & {$[6]$} & {$[5]$} \\
\hline Lauric & C 12:0 & 0.00 & 0.00 & 0.00 \\
Myristic & C 14:0 & 0.00 & 0.00 & 0.07 \\
Palmitic & C 16:0 & 10.43 & 10.5 & 10.36 \\
Palmitoleic & C 16:1 & 0.00 & 0.00 & 0.19 \\
Stearic & C 18:0 & 8.21 & 7.2 & 9.04 \\
Oleic & C 18:1 & 61.36 & 65.4 & 63.38 \\
Linoleic & C 18:2 & 19.48 & 16.0 & 16.17 \\
Linolenic & C 18:3 & 0.52 & 0.00 & 0.29 \\
Arachidic & C 20:0 & 0.00 & 0.00 & 0.67 \\
Eicosenoic & C 20:1 & 0.00 & 0.00 & 0.00 \\
Behenic & C 22:0 & 0.00 & 0.00 & 0.07 \\
Erucic & C 22:1 & 0.00 & 0.00 & 0.00 \\
Lignoceric & C 24:0 & 0.00 & 0.00 & 0.00 \\
\hline
\end{tabular}

${ }^{\mathrm{a}}$ Carbon content (CC) per double bonds (DB)

Table 2 Chemical composition of coconut biodiesel

\begin{tabular}{llccc}
\hline Fatty acid & CC:DB & \multicolumn{3}{c}{ Coconut biodiesel composition $(\%)$} \\
\cline { 3 - 5 } & & This work & {$[8]$} & {$[5]$} \\
\hline Caprylic & C $8: 0$ & 6.10 & 6.46 & 0.00 \\
Capric & C 10:0 & 5.93 & 5.62 & 0.00 \\
Lauric & C 12:0 & 47.20 & 46.91 & 64.44 \\
Myristic & C 14:0 & 18.50 & 18.74 & 20.45 \\
Palmitic & C 16:0 & 8.90 & 9.69 & 7.71 \\
Palmitoleic & C 16:1 & 0.00 & 0.00 & 0.09 \\
Stearic & C 18:0 & 3.10 & 2.83 & 1.73 \\
Oleic & C 18:1 & 7.30 & 6.83 & 4.61 \\
Linoleic & C 18:2 & 1.50 & 2.21 & 0.96 \\
Linolenic & C 18:3 & 0.00 & 0.00 & 0.00 \\
Arachidic & C 20:0 & 0.00 & 0.10 & 0.04 \\
Eicosenoic & C 20:1 & 0.00 & 0.00 & 0.00 \\
Erucic & C 22:1 & 0.00 & 0.00 & 0.00 \\
\hline
\end{tabular}

results here obtained closely resemble those by [8]. Both show the highest quantitative difference from the concentration of lauric acid (C12:0) found by [5].

Cotton biodiesel presents a chemical composition with high concentration of linoleic acid (C18:2) $(53.14 \%$ to $58 \%)$, followed by palmitic acid (C16:0) $(24.90-28.70 \%)$ and oleic acid (C18:1) (13-18.93\%) (Table 3). Thus, this biodiesel type is more likely to be oxidized and degraded, requiring storage with high concentrations of antioxidant additives. The component concentrations found in this work are in close agreement with those found by $[8,13]$ and in reasonable agreement with the results found by $[10,11]$. 
The physical-chemical properties obtained for cashew, coconut and cotton crude oil and biodiesel attend ASTM D6751-12 specifications (Tables $4,5,6$ ). The acid number of all crude oil studies was higher than that of the corresponding biodiesel. No significant change of biodiesel iodine value was observed in comparison with the corresponding crude oil. The iodine value was coherent with the fatty acid methyl ester chemical composition, showing the lowest value for coconut biodiesel (saturated), followed by cashew (monounsaturated) and cotton (diunsaturated). Copper corrosion tests showed low values for all crude oils and biodiesel tested.

Cashew biodiesel density and viscosity here obtained have close values to the ones presented by [5] (Table 4). The properties of cashew crude oil have not been found in the literature for comparison purpose. Coconut biodiesel

Table 3 Chemical composition of upland cotton biodiesel

\begin{tabular}{lllrrrr}
\hline Fatty acid & CC:DB & \multicolumn{5}{c}{ Cotton biodiesel composition (\%) } \\
\cline { 3 - 7 } & & \multicolumn{1}{c}{ This work } & {$[8]$} & {$[13]$} & {$[11]$} & {$[10]$} \\
\hline Caprylic & C $8: 0$ & 0.00 & 0.00 & 0.00 & 0.00 & 0.00 \\
Capric & C 10:0 & 0.00 & 0.00 & 0.00 & 0.00 & 0.00 \\
Lauric & C 12:0 & 0.00 & 0.00 & 0.00 & 0.00 & 0.00 \\
Myristic & C 14:0 & 0.00 & 0.72 & 0.00 & 0.00 & 0.00 \\
Palmitic & C 16:0 & 25.43 & 25.93 & 24.90 & 28.70 & 28.00 \\
Palmitoleic & C 16:1 & 0.00 & 0.00 & 0.00 & 0.00 & 0.00 \\
Stearic & C 18:0 & 2.21 & 1.74 & 2.63 & 0.90 & 1.00 \\
Oleic & C 18:1 & 15.36 & 15.98 & 18.93 & 13.00 & 13.00 \\
Linoleic & C 18:2 & 54.48 & 55.12 & 53.14 & 57.40 & 58.00 \\
Linolenic & C 18:3 & 0.52 & 0.16 & 0.00 & 0.00 & 0.00 \\
Arachidic & C 20:0 & 0.10 & 0.22 & 0.29 & 0.00 & 0.00 \\
Eicosenoic & C 20:1 & 0.00 & 0.07 & 0.00 & 0.00 & 0.00 \\
Erucic & C 22:1 & 0.00 & 0.00 & 0.00 & 0.00 & 0.00 \\
\hline
\end{tabular}

viscosity here determined is also in agreement with the value presented by [5] (Table 5). However, the iodine value here found for coconut biodiesel is higher than that reported by [5], which is probably a consequence from the different compositions found for the saturated fatty acids (see Table 2).

All properties of cotton biodiesel here determined resemble those found in the literature (Table 6). In general, the properties of cotton crude oil here found are in good agreement with the results obtained by [1], with exception of a much higher acid number, which may be a reflection of the storage process of the crude oil. Both this work and the one by [1] show cotton crude oil viscosity much higher than that presented by [2], and much lower than the one described by [12].

One of the most important biodiesel properties is kinematic viscosity, as it affects fuel injection in the engine. The viscosity of the studied biodiesel types was much lower than that of the corresponding crude oils, thanks to the transesterification process. The high viscosity of crude oils is the main obstacle for their direct use in diesel engines [15]. The viscosity of all biodiesel types tested attended ASTM D6751-12 standard (Tables 4, 5, 6). Increasing temperature causes the fuel to flow more easily, being favorable to fuel injection efficiency and atomization. Low temperatures reduce fuel fluidity, as fuel viscosity is increased (Fig. 4).

The density of the biodiesel types tested presented a slight reduction in comparison with the corresponding crude oils, and is within the recommended range by ASTM D6751-12 standard (Tables 4, 5, 6). In general, biodiesel density is decreased with increasing temperature (Fig. 5). High fuel density causes increased fuel consumption and exhaust emissions of particulate matter, unburned hydrocarbons and carbon dioxide.

Table 4 Physical-chemical properties of cashew crude oil and biodiesel

\begin{tabular}{|c|c|c|c|c|}
\hline \multirow[t]{2}{*}{ Property } & \multirow{2}{*}{$\begin{array}{l}\text { Cashew crude oil } \\
\text { This work }\end{array}$} & \multicolumn{2}{|c|}{ Cashew biodiesel } & \multirow[t]{2}{*}{ ASTM D6751 } \\
\hline & & This work & {$[5]$} & \\
\hline Density@ $@ 20^{\circ} \mathrm{C}\left(\mathrm{kg} / \mathrm{m}^{3}\right)$ & 920 & 890 & - & $850-900$ \\
\hline Viscosity @ $40{ }^{\circ} \mathrm{C}\left(\mathrm{mm}^{2} / \mathrm{s}\right)$ & 27.23 & 4.32 & 3.69 & $1.9-6.0$ \\
\hline Acid number (mg KOH/g) & 1.60 & 0.50 & - & $\leq 0.50$ \\
\hline Iodine value $\left(\mathrm{g} \mathrm{I}_{2} / 100 \mathrm{~g}\right)$ & 83.0 & 82.50 & 86.65 & - \\
\hline Copper corrosion strip & $1 b$ & $1 b$ & - & $\operatorname{Max} 3$ \\
\hline Peroxide index $\left(\mathrm{meqO}_{2} / \mathrm{Kg}\right)$ & 1.39 & 0.92 & - & - \\
\hline Saponification index $(\mathrm{mgKOH} / \mathrm{g})$ & 175.4 & 145.2 & 201 & - \\
\hline Water content $(\mathrm{mg} / \mathrm{Kg})$ & 536 & 312.35 & - & Max 500 \\
\hline Free glycerin $(\% \mathrm{wt} / \mathrm{wt})$ & - & 0.01 & . & 0.02 \\
\hline Total glycerin (\% wt/wt) & - & 0.12 & . & 0.24 \\
\hline Methanol content (\% wt/wt) & - & 0.1 & - & 0.2 \\
\hline Cetane number & - & 56.40 & 54.03 & $\operatorname{Min} 47$ \\
\hline
\end{tabular}


Table 5 Physical-chemical properties of coconut crude oil and biodiesel

\begin{tabular}{|c|c|c|c|c|}
\hline \multirow[t]{2}{*}{ Property } & \multirow{2}{*}{$\begin{array}{l}\text { Coconut crude oil } \\
\text { This work }\end{array}$} & \multicolumn{2}{|c|}{ Coconut biodiesel } & \multirow[t]{2}{*}{ ASTM D675 } \\
\hline & & This work & {$[5]$} & \\
\hline Density @ $20^{\circ} \mathrm{C}\left(\mathrm{kg} / \mathrm{m}^{3}\right)$ & 910 & 870 & - & $850-900$ \\
\hline Viscosity@ $40{ }^{\circ} \mathrm{C}\left(\mathrm{mm}^{2} / \mathrm{s}\right)$ & 28.80 & 2.80 & 2.30 & $1.9-6.0$ \\
\hline Acid number (mg KOH/g) & 2.22 & 0.19 & - & $\leq 0.50$ \\
\hline Iodine value $\left(\mathrm{g} \mathrm{I}_{2} / 100 \mathrm{~g}\right)$ & 8.10 & 10.12 & 5.98 & - \\
\hline Copper corrosion strip & $1 \mathrm{~b}$ & $1 b$ & - & Max 3 \\
\hline Peroxide index $\left(\mathrm{meqO}_{2} / \mathrm{Kg}\right)$ & 1.05 & 0.86 & - & - \\
\hline Saponification index $(\mathrm{mgKOH} / \mathrm{g})$ & 155.4 & 151.2 & 262 & - \\
\hline Water content $(\mathrm{mg} / \mathrm{Kg})$ & 487 & 230.25 & - & Max 500 \\
\hline Free glycerin $(\% \mathrm{wt} / \mathrm{wt})$ & - & 0.018 & - & 0.02 \\
\hline Total glycerin (\% wt/wt) & - & 0.11 & - & 0.24 \\
\hline Methanol content (\% wt/wt) & - & 0.1 & - & 0.2 \\
\hline Cetane number & - & 63.73 & 65.80 & Min 47 \\
\hline
\end{tabular}

Table 6 Physical-chemical properties of upland cotton crude oil and biodiesel

\begin{tabular}{|c|c|c|c|c|c|c|c|}
\hline \multirow[t]{2}{*}{ Property } & \multicolumn{4}{|c|}{ Cotton crude oil } & \multicolumn{2}{|c|}{ Cotton biodiesel } & \multirow[t]{2}{*}{ ASTM D6751 } \\
\hline & This work & {$[1]$} & {$[2]$} & {$[12]$} & This work & {$[13]$} & \\
\hline Density @ $20^{\circ} \mathrm{C}\left(\mathrm{kg} / \mathrm{m}^{3}\right)$ & 930 & 915 & 910 & 912 & 880 & 875 & $850-900$ \\
\hline Viscosity@ $40{ }^{\circ} \mathrm{C}\left(\mathrm{mm}^{2} / \mathrm{s}\right)$ & 35.20 & 33.5 & 18.20 & 50.00 & 4.75 & 4.07 & $1.9-6.0$ \\
\hline Acid number (mg KOH/g) & 8.20 & 0.16 & - & 0.11 & 0.35 & 0.16 & $\leq 0.50$ \\
\hline Iodine value $\left(\mathrm{g} \mathrm{I}_{2} / 100 \mathrm{~g}\right)$ & 108.80 & 104.7 & - & - & 112.40 & - & - \\
\hline Copper corrosion strip & $1 \mathrm{~b}$ & - & - & - & $1 \mathrm{~b}$ & $1 \mathrm{a}$ & $\operatorname{Max} 3$ \\
\hline
\end{tabular}

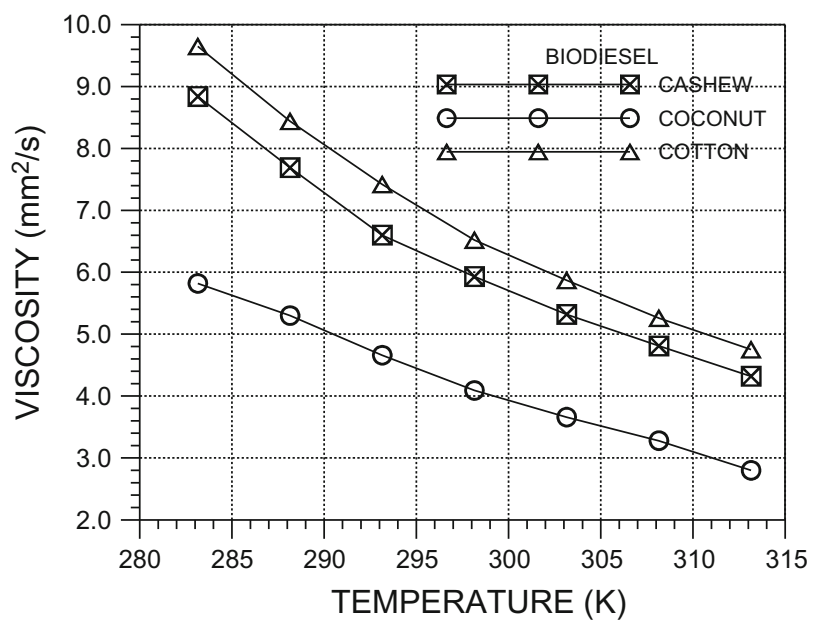

Fig. 4 Decrease of biodiesel viscosity with increasing temperature

The other physical-chemical properties that indicate coconut and cashew biodiesel quality, such as water content, total and free glycerin content, methanol content and cetane number, shown in Tables 4 and 5, attend the ASTM 6751 standard for biodiesel quality. These results indicate that both materials, coconut and cashew, are potential sources to obtain high-quality biofuels.

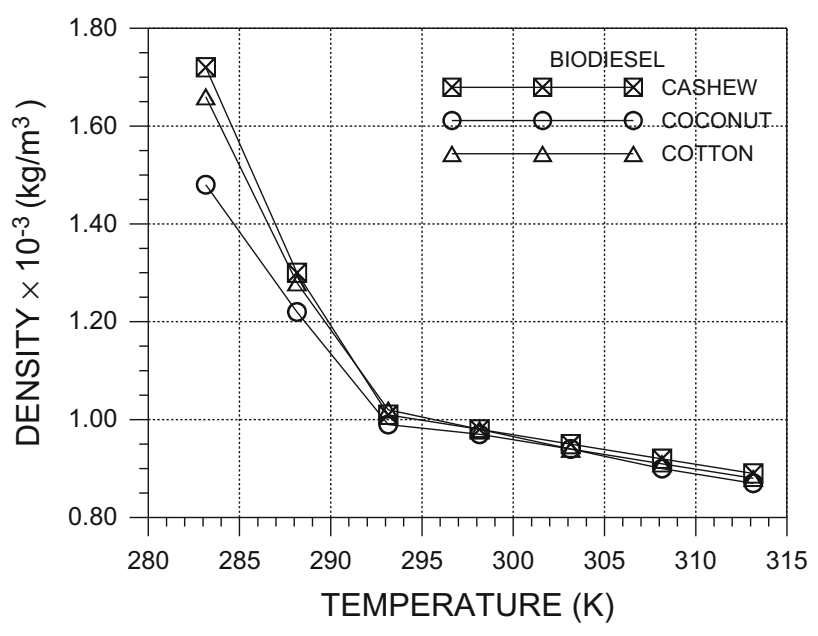

Fig. 5 Decrease of biodiesel density with increasing temperature

\section{Conclusions}

The potential biodiesel sources studied-cashew (Anacardium occidentale $L$ ), coconut (Cocos nucifera) and upland cotton (Gossypium hirsutum) - are all rich in fatty acids and allows for fast biodiesel production processes. The physicalchemical properties of the biodiesel produced from those 
sources attend the ASTM D6751-12 standard (ASTM, 2012c) for biodiesel specification. From the chemical composition of the fatty acid methyl esters, cashew biodiesel presented the highest oleic acid concentration, being an indication of its high oxidation stability. The presence of high concentrations of saturated fatty acids in coconut biodiesel may limit its use under low temperatures. The composition of cotton biodiesel indicates that, among the sources tested, it is the most likely to be oxidized and degraded.

Acknowledgments The authors thank Universidad de Córdoba for the financial support to this work. Thanks are also due to CNPq and FAPEMIG.

Open Access This article is distributed under the terms of the Creative Commons Attribution License which permits any use, distribution, and reproduction in any medium, provided the original author(s) and the source are credited.

\section{References}

1. Borugadda, V.B., Goud, V.V.: Biodiesel production from renewable feedstocks: status and opportunities. Renew Sustain Energy Rev 16, 4763-4784 (2012)

2. Leung, D.Y., Xuan, W., Leung, M.K.H.: A review on biodiesel production using catalyzed transesterification. Appl Energy 87, 1083-1095 (2010)

3. Murugesan, A., Umarani, C., Chinnusamy, T.R., Krishnan, M., Subramanian, R., Neduzchezhain, N.: Production and analysis of bio-diesel from non-edible oils-a review. Renew Sustain Energy Rev 13, 825-834 (2009)

4. Lafont, J.J., Pàez, M.S., Portacio, A.A.: Extracción y caracterización fisicoquímica del aceite de la semilla (almendra) del marañón (Anacardium occidentale L). Inf Tecnol 22, 51-58 (2011)
5. Winayanuwattikun, P., Kaewpiboon, C., Piriyakananon, K., Tantong, S., Thakernkarnkit, W., Chulalaksananukul, W., Yongvanich, T.: Potential plant oil feedstock for lipase-catalyzed biodiesel production in Thailand. Biomass Bioenergy 32, 1279-1286 (2008)

6. Adeyeye, E.I.: Fatty acid composition of zonocerus variegatus, macrotermes bellicosus and anacardium occidentale kernel. Int $\mathbf{J}$ Pharma Bio Sci 2, 135-144 (2011)

7. Sun, J., Yu, B., Curran, P., Liu, S.Q.: Quantitative analysis of volatiles in transesterified coconut oil by headspace-solid-phase microextraction-gas chromatography-mass spectrometry. Food Chem. 129, 1882-1888 (2011)

8. Giakoumis, E.G.: A statistical investigation of biodiesel physical and chemical properties, and their correlation with the degree of unsaturation. Renewable Energy 50, 858-878 (2013)

9. Anwar, F., Rashid, U., Knothe, G.: Evaluation of biodiesel obtained from cottonseed oil. Fuel Process. Technol. 90, 1157-1163 (2009)

10. Goering, C.E., Schwab, A.W., Daugherty, M.J., Pryde, E.H., Heakin, A.J.: Fuel properties of eleven oils. Trans ASAE 25, 1472-1483 (1982)

11. Demirbas, A.: Biodiesel fuels from vegetable oils via catalytic and non-catalytic supercritical alcohol transesterifications and other methods: a survey. Energy Convers. Manage. 44, 2093-2109 (2003)

12. Meng, X., Chen, G., Wang, Y.: Biodiesel production from waste cooking oil via alkali catalyst and its engine test. Fuel Process Technol. 89, 851-857 (2008)

13. Rashid, U., Anwar, F., Knothe, G.: Evaluation of biodiesel obtained from cottonseed oil. Fuel Process. Technol. 90, 1157-1163 (2009)

14. Bamgboye, A., Hansen, A.: Prediction of cetane number of biodiesel fuel from the fatty acid methyl ester (FAME) composition. Int Agrophy 22, 21-29 (2008)

15. Refaat, A.A.: Correlation between the chemical structure of biodiesel and its physical properties. Int. J. Environ. Sci. Tech. 6, 677-694 (2009) 